\title{
NOTAS SOBRE USOS Y CONSUMOS LITERARIOS
}

\begin{abstract}
Alfredo SALDAÑA
Universidad de Zaragoza

$\mathrm{H}$ asta qué punto somos capaces de pensar el estatuto literario al margen de la circulación social de la propia literatura?, ¿en qué medida y con qué rigor podemos ofrecer una idea siquiera aproximada de lo que pueda representar la literatura si no es a la luz de las condiciones de su recepción?, ¿con qué rigor es posible hablar de la literatura como un lenguaje que se caracteriza por la ausencia o, cuando menos, la volatilidad de factores estéticos específicos?, rasgos que, sin embargo, no impidieron a teóricos como Sklovski, Jakobson, Wellek y Warren, entre otros, defender la existencia de un uso singularmente literario del lenguaje en el que la función estética es la dominante, un hábito que se inicia en una experiencia privada, íntima, y se materializa en una dimensión social orientada hacia la búsqueda de un horizonte de sentidos compartidos por el autor y los lectores, un espacio en el que la literatura es resultado de un intercambio comercial generado por el consumo. A la luz de dicha dimensión, hay una tendencia muy generalizada que asocia el sintagma preposicional «de consumo» con un número considerablemente elevado de lectores (dando por hecho, cosa nada segura, que tras cada uno de esos compradores-consumidores hay un lector), como si, por otra parte, la lectura de determinados textos literarios sensiblemente minoritarios no pudiera considerarse una actividad consumista.

Es evidente que la cuestión del consumo, en este caso, tiene que ver con la recepción, esa práctica que transforma la escritura en literatura, con la que una actividad privada se prolonga en una acción social y que confirma la sentencia blanchotiana según la cual un texto que no se lee es un texto que todavía no se ha escrito; es indudable también que dicha actividad, en su proyección pública, se encuentra más vinculada con categorías como el valor de cambio o la mercancía que con el valor de uso, más próxima al mercado literario que a la estética literaria y que, en un mundo lastrado por un capitalismo económico, cultural y cognitivo arrollador, cuanto más amplia sea esa recepción más valor y autoridad alcanzarán los objetos consumidos en el campo literario. En fin, todo esto forma parte de esos prejuicios que han hecho costra en la piel de nuestro imaginario colectivo orientando actitudes, gustos y sensibilidades. Así pues, sería muy conveniente levantar esa capa para quizás entrever que lo que se oculta bajo su superficie es reflejo de la diversidad y complejidad del mundo y no solo, aunque también, de los intereses del mercado.
\end{abstract}


A estas alturas no deja de ser un lugar común el hecho de señalar que la literatura adquiere sentido como práctica significativa en su circulación social, un movimiento controlado en gran medida por agentes económicos (medios de comunicación de masas, grandes corporaciones, multinacionales y empresas financieras con intereses en el sector editorial, etc.) que regulan y fiscalizan la circulación literaria manipulando los gustos e intereses de los lectores. Ahora bien, durante buena parte de la historia cultural de la humanidad, las obras literarias se han entendido como creaciones merecedoras de aprecio y no como construcciones valoradas en función de la mejor o peor respuesta comercial que hayan tenido. Si nos fijamos en las muy diversas funciones que la literatura ha desempeñado a lo largo del tiempo, es un hecho que se trata de una actividad en la que encontramos numerosos perfiles, nada, por lo tanto, esencial, dotada además de una gran diversidad temática y formal. Sucede que incluso entre las diferentes modalidades con mayor proyección social en el amplísimo abanico que muestra la narrativa contemporánea (la ficción histórica, la narrativa de la memoria, la novela social, el relato metaliterario, la novela rosa, la novela negra, la narración culturalista, la confesión, el testimonio cargado de anécdotas (auto)biográficas más o menos irrelevantes, la novela experimental, la nueva novela policíaca, la novela de ciencia-ficción, etc.), entre todas esas variedades, no somos capaces de hallar, al margen de una respuesta comercial más o menos considerable, un nexo genérico, formal, estilístico, estructural o temático que otorgue a esas modalidades un mismo aire de familia; más aún, cabría añadir que es solo esa respuesta comercial, ligada a los diferentes gustos e intereses consumistas, la única guía rectora capaz de orientar el trabajo de ciertos escritores por unos u otros senderos, unos profesionales que, llegado el caso, hipnotizados por las prebendas que otorga el mercado (entre las que se encuentran el beneficio económico, el reconocimiento social y las sinecuras derivadas), no dudarán en traicionar -si es que alguna vez las tuvieron - sus ideas literarias y se decantarán por las formas, géneros y registros de mayor aceptación comercial.

En todo caso, y teniendo en cuenta que, por supuesto, el éxito comercial y la calidad literaria pueden compartir un mismo lugar, se trata de una idea que demanda algún tipo de reajuste conceptual y que ha ido perdiendo parte de su eficacia en estos últimos años, conforme se ha intensificado el proceso de la globalización y con él una cierta posmodernidad enemistada con las ideas de crítica y conflicto y proclive a entender y describir el mundo de una manera superficial y autocomplaciente. En ese espectáculo participan editores que, obsesionados por la rentabilidad económica, han olvidado la dimensión cultural de su actividad profesional y escritores que desarrollan su trabajo a la sombra de la ansiedad no de la influencia sino de la celebridad. Y editores y escritores como esos encuentran su correlato adecuado y necesario no en una comunidad de lectores con espíritu crítico sino en unos consumidores de lecturas que entienden dicha ocupación como un ingrediente más de su ocio. El editor que ha conquistado una cuota de mercado luchará con todas sus fuerzas materiales por mantener e incluso aumentar su presencia económica en el mismo. Con su trabajo, la escritura, el escritor contribuye a configurar y mantener el mercado, y este le corresponde con sus reconocimientos económicos. Es un toma y daca en el que la literatura adopta la 
114 Tropelías. Revista de Teoría de la Literatura y Literatura Comparada, número extraordinario 2 (2017) Alfredo Saldaña

forma de una cosa mueble destinada a ser consumida por un cliente. $\mathrm{Y}$ en todo ese entramado participa un lector particular, el crítico literario, un espécimen cuyo perfil aparece ya dibujado en la Poética aristotélica que entiende en ocasiones su trabajo no de una manera independiente sino como un publicista, un vocero vendido al servicio de determinados privilegios sociales e intereses comerciales. En estas circunstancias - en las que el texto literario se concibe fundamentalmente como una mercancía-, parece más una excepción a la regla que una norma habitual de conducta el hecho de que el escritor asuma compromisos con el lenguaje, la escritura, la estética, etc.; en esas mismas coyunturas, que el lector entienda el consumo como una oportunidad para ejercer su libertad de elección en un abanico amplísimo de posibilidades es, en realidad, casi siempre, una falacia dada la apabullante banalización de propuestas literarias y la creciente concentración de empresas editoras, medios de comunicación y puntos de venta en unos pocos oligopolios. Claro que hay excepciones y quien escarbe un poco por debajo de la superficie encontrará escritores comprometidos con su oficio, sellos editoriales que no buscan solo la plusvalía económica, medios de comunicación interesados en contar la realidad de otras maneras y librerías en donde los textos literarios son algo más que unos meros productos de intercambio comercial.

Y al margen de todo tipo de factores que ponen en cuestión el estatuto de la literatura, es un hecho que en la actualidad la función de la literatura es carecer de función, por lo menos en los sentidos de utilidad, rentabilidad y razón económica que usualmente hemos atribuido a este sustantivo, probablemente por resultar esos sentidos - en realidad, similares versiones de un mismo sentido- los únicos dominantes. Sin embargo, esa funcionalidad ha sido en ocasiones un elemento decisivo y se ha entendido de muy diversas maneras a lo largo de la historia, de tal modo que la práctica literaria se ha asociado al fomento de creencias religiosas y valores morales, sistemas políticos y culturales, métodos terapéuticos y balsámicos. La literatura funciona entonces como una válvula de escape, un antídoto con el que la gente afronta unas vidas marcadas por la carencia, la adversidad y la violencia generadas por un sistema radicalmente injusto; y cuando la literatura funciona de esa manera suele encontrar la horma de su zapato en lectores que encuentran en la literatura una vía de evasión de la realidad, una oportunidad para vivir otras vidas, asumiendo como real el modelo ilusorio y ficticio de existencia de una clase hegemónica que la propia literatura se encarga de ensalzar; de este modo, la literatura de evasión, en el fondo, actúa como una forma de invasión de la ideología dominante en la vida corriente.

Nos encontramos, de este modo, con una práctica literaria bastante extendida que enmascara una realidad que se percibe como algo fundamentalmente desagradable y molesto y, para ello, se apuesta por textos literarios que no buscan sino la complacencia y la complicidad de los lectores, operación que se produce a partir de un elemento constitutivo fundamental en todo este proceso: el mercado. En tanto que el neoliberalismo económico supone la capitalización y rentabilización de la realidad, esto es, en palabras de Perry Anderson (2000: 78), «la saturación de cada poro del mundo por el suero del capital», la literatura no puede explicarse al margen de ese capital, que todo lo invade y devora. La literatura no existe sin el mercado, ante cuyo altar se postra con la intención de 
adorarlo. Si la lógica capitalista reconoce la literatura en tanto que mercancía, el autor no puede sino asumir su papel de productor (la figura del trabajador sustituye a la imagen romántica del genio creador) de dicha mercancía. Marx ya entrevió esto al señalar que «un escritor es un obrero productivo, no porque produzca ideas, sino porque enriquece a su editor» (1945: 176). Así las cosas, hace unos años Ignacio Echevarría (2005) afirmaba que hemos pasado de la novela social a la novela sociable, una novela en la que:

El imperativo común pasó a ser la seducción. Se trataba de seducir al lector, de establecer con él una relación cómplice. Nada de actitudes incomodadoras. El fantasma de la narrativa social se conjuró mediante una narrativa sociable. Esta nueva sociabilidad impuso el éxito como arancel o canon necesario en el tráfico de la literatura en la sociedad (2005: 35-36).

La seducción del lector constituye un elemento básico en el entramado literario actual y es un requisito imprescindible para alcanzar dicho éxito; por añadidura, dicha seducción ha de producirse sin que parezca una conquista, aunque lo sea, y sin que el lector tenga la sensación de haber sido derrotado en sus convicciones; además, por medio de un discurso amable y tentador, el lector acepta ser engañado y asume sin demasiados problemas el discurso de la clase dominante.

Como recuerda Terry Eagleton (2013), los ideólogos literarios en la Inglaterra victoriana se mostraron partidarios de extender entre la población el gusto por la lectura de unas obras literarias que podía provocar la evasión e incluso el olvido no solo de las lamentables condiciones materiales en que vivían sino también de las causas que habían generado esas situaciones; en esos casos, la lectura literaria se presentaba como una alternativa a la revolución. Frente a ese tipo de literatura autocomplaciente y evasiva, es un hecho que existe otro tipo de literatura política -aunque quizás habría que preguntarse cuál en cierto modo no lo es-en la que «revolución de lenguaje y lenguaje de la revolución no sean marbetes antagónicos» (Sanz, 2014: 82), una literatura que no deje de cuestionar los límites entre los géneros y en la que la lectura sea una experiencia marcada por el desafío y la incertidumbre, la ventana abierta a un paisaje que se encuentra todavía por descubrir. Desde este punto de vista, esa experiencia no puede darse con una literatura orientada hacia el consumo y en la que la ideología consumista condiciona su propia práctica puesto que en dicho escenario la lectura suele responder a estereotipos y fórmulas prefijadas de antemano por unos think tanks y una maquinaria mediática que trabajan en una misma dirección, en función de unos mismos intereses. Es evidente que esos bancos de opinión y esos medios de comunicación de masas suelen compartir objetivos económicos y, en ese sentido, sus estrategias pasan por publicitar textos que alaban los fundamentos del sistema social imperante, textos que se encuentran más cerca de los sermones, los catecismos, las loas, los manifiestos o los panfletos que de la literatura.

El mercado es el lugar en el que muchos escritores encuentran su particular Shangri-La, un territorio cuya meta no es traspasar los límites del tiempo y del espacio sino consumirse -en su doble acepción semántica- en un instante efímero: el libro tiene que ser consumido de forma inmediata para que su lugar en la librería o en el centro comercial sea ocupado por otro libro. El capitalismo salva (condenándolos al ostracismo) del fuego devorador del mercado a aquellos libros que no 
cumplen con la única finalidad de este sistema social y económico: la rentabilidad, el beneficio. La masificación de la producción literaria conlleva la aparición de una literatura kleneex, una modalidad perecedera, fugaz, consumible, con una fecha de caducidad marcada por la rentabilidad inmediata. Ahora bien, es evidente que -cuando la literatura entra en la siniestra lógica del mercado y el lector se convierte en un sujeto pasivo o, sin más, en un mero consumidor- ese valor de uso se transforma en un valor de cambio. En este sentido, a finales de la pasada década de los ochenta, se comenzó a hablar de una novela light, una novela ligera, despreocupada y superficial que nacía con el claro propósito de no incomodar al lector y que se caracterizaba por su falta de complejidad formal y estructural, sus contenidos fácilmente digestibles y su carácter de material desechable tras la lectura. Un producto, en definitiva, de usar y tirar. En esto se ha convertido gran parte de la literatura que se publica en la actualidad, sometida a los vaivenes e intereses del mercado. El capitalismo avanzado reduce la literatura a mera mercancía programada para llevar una vida efímera y dotada de un determinado valor de cambio, convirtiéndola en un producto perecedero, envasado con fecha de caducidad. La búsqueda de la posteridad queda sustituida, en la literatura de consumo, por la obsolescencia programada.

Me gustaría que estas notas -redactadas de manera un tanto atropellada- sirviesen para recordar algo obvio: la literatura -como la sociedad en la que surge - es siempre resultado de conflictos, tensiones y enfrentamientos de distintos tipos y esas situaciones se dan en todos sus géneros y modalidades, incluidas aquellas que -sometidas a los vaivenes del consumo-pertenecen a la matriz que conocemos con el nombre de cultura de masas, una denominación que, tal como defendió Raymond Williams en Culture and society (1958), más que nombrar una realidad -la propia existencia de una comunidad como masa más o menos homogénea-, indica una deriva, una actitud desindividualizadora orientada hacia la estandarización, el control social y el tratamiento de la gente como un sujeto colectivo. Sin embargo, y sin negar ninguna de estas premisas, es evidente que la literatura puede servir también para abrir fracturas en los cimientos sobre los que se asienta esa misma comunidad, y presentarse como un lugar idóneo para practicar la crítica de todos los valores y modelos que regulan la vida social de ese mismo combinado, una crítica por la que algunos escritores han pagado un precio muy alto (ahí están Danilo Kis, acusado, por sus colegas más próximos al poder, de falsear y traicionar la historia en Una tumba para Boris Davidovich, Salman Rushdie, amenazado de muerte por una fetua del imán Jomeini a raíz de Los versos satánicos, y, más recientemente, Roberto Saviano, igualmente amenazado por diversas familias camorristas tras la publicación en 2006 de Gomorra). Alimentados por un ciego e indiscriminado odio hacia el arte y la ficción, hemos llegado a una situación en que «la literatura se encuentra sometida a una violencia sin precedentes en su historia» y en que la censura persigue «la ficción en tanto que tal y pretende transformar en delito todo tipo de práctica artística libre» (Salmon, 2001: 11). Kis -para quien el nacionalismo era una ideología banal y totalitaria-, Rushdie, Saviano, supervivientes de un mismo naufragio provocado por la intransigencia y el terror. 
En todos estos casos son los textos literarios los que se perciben como transgresores de un determinado sistema - político, religioso, económico-y, así, conductas de este tipo no suponen sino atentados contra lo que, desde un ámbito imaginario y ficcional, apuesta por la emergencia de otros mundos reales y otros modos de relación entre los hombres. De esta forma, frente a un mundo cultural y económicamente cada día más estandarizado y uniformado (como una consecuencia evidente de la globalización), teledirigido por las grandes empresas de comunicación y las industrias culturales transnacionales, es urgente plantear la oposición de una acción política que reivindique el poder subversivo de la ficción y de otras manifestaciones de creación simbólica, una acción que ponga en contacto, sobre todo, a los que son obligados a callar y a los que no se les permite escribir con quienes no tienen la oportunidad de escuchar o leer. Y dicha acción pasa por volver a leer, redefiniendo el concepto de lectura, añadiendo a su significado un componente de crítica para, de ese modo, reescribir nuestra tradición literaria. Leer críticamente implica entonces saber quién escribe, para quién escribe y desde dónde escribe; y, sobre todo, ser consciente de que la literatura no se encuentra en los márgenes de las estructuras sociales e históricas, sino que es una instancia más de la producción y reproducción ideológicas; así, se trata de practicar otra lectura de los textos que forman parte de lo que se ha convenido en llamar canon literario.

Una crítica comprometida fundamentalmente con la literatura debería enfrentarse ideológicamente contra quienes imponen una visión de lo literario totalmente desgajada de su historicidad y, aunque la literatura es una práctica de transmisión y legitimación ideológicas, habría que recordar que la ideología nunca se presenta de forma pura; en su interior se localizan las luchas de clases y las contradicciones históricas entre los distintos modos de producción que combaten en una coyuntura histórica específica. Ese hecho hace posible la existencia de una literatura crítica y disidente porque, mientras exista la lucha de clases, en el interior de la ideología florecerán elementos residuales, emergentes y, por supuesto, dominantes. En este sentido, si esa literatura disidente adquiere la apariencia del best seller, sus posibilidades revolucionarias pueden llegar a multiplicarse, en la medida que alcanzan a un mayor número de lectores. En esta línea, el marxista italiano Antonio Gramsci exponía su teoría de la «producción artística popular», considerando que la literatura de consumo, con un proyecto ideológico y social firme, puede ser útil para la transformación revolucionaria de la sociedad y que «solo entre los lectores de la literatura folletinesca se puede encontrar el público suficiente y necesario para crear la base cultural de la nueva literatura» (1973: 269). El folletín de nuestros días se encuentra en gran medida en la novela histórica, de la memoria, de intriga o de aventuras, modalidades que cuentan con una gran repercusión social, razón por la que -si se dan determinadas condiciones- pueden convertirse en formas literarias idóneas en un escenario de lucha contra-hegemónica. Pero eso es solo una posibilidad que podrá o no materializarse dado que desde los distintos estamentos de poder se promueve el gusto por lo política y culturalmente correcto, y la corrección, casi siempre, se entiende como la asunción de normas y valores socialmente consolidados; en la práctica literaria dicha 


\section{Alfredo Saldaña}

corrección se materializa en aquellas propuestas que se desmarcan de cualquier actitud manifiestamente crítica y optan por miradas lúdicas, festivas, conciliadoras y autocomplacientes.

En el escenario actual sobre las implicaciones de los intercambios y los conflictos culturales, es cada día más frecuente encontrar planteamientos favorables a las particularidades de la diferencia y la interculturalidad. Así, conceptos como multiculturalidad, apertura de paradigmas, pluralismo crítico, elasticidad o flexibilidad teóricas van recubriéndose de una especie de aureola de gloria que otorga prestigio a la vez que, al mismo tiempo, conllevan imprecisiones terminológicas, semánticas e ideológicas. Este proyecto crítico se desarrolla a través de una deliberada confluencia epistemológica y de métodos interpretativos que apuestan por el bricolaje, la apertura, la movilidad y la coparticipación de enfoques, es decir, por sumar y no restar, desde la conciencia de que el conocimiento avanza de forma eficaz únicamente en un escenario caracterizado por la diversidad y que el itinerario que traza el excluyente monopolio del saber es, a medio o largo plazo, el itinerario de la cerrazón ideológica. De todas maneras, no es suficiente con prestar atención a la diversidad, riqueza y complejidad que se esconden detrás de esas diferentes categorías, más próximas al ámbito del simulacro que al de lo real; haría falta, en mi opinión, ahondar en los motivos que han conducido a la construcción de un armazón ideológico al servicio del mercado y del capital y, en ese sentido, una literatura crítica y revolucionaria tendría que incluir en su proyecto la visibilización de los mecanismos invisibles que provocan nuestra explotación, llamar la atención sobre el modo en que las distintas violencias subjetivas que se producen en el sistema -reyertas callejeras, delincuencia, mobbing escolar o laboral, etc.- son, en realidad, provocadas por una violencia objetiva o sistémica que define la propia lógica de las relaciones de explotación del capitalismo avanzado (Žižek, 2010).

Movimiento y transformación frente a parálisis y estatismo, la frontera es una oportunidad para el contacto y el reconocimiento de territorios diferentes -y esas diferencias no pueden ser nunca la excusa para impulsar relaciones sociales basadas en el dominio de unas actitudes sobre otras-, la metáfora espacial más significativa de una posmodernidad que ha hecho del dinamismo y la inestabilidad algunas de sus señas identitarias. En esas circunstancias, cierta literatura -al hilo de una actitud radicalmente crítica que entiende la cultura no como fiesta y celebración sino como un lugar de confrontación y exposición de tensiones sociales y políticas- hunde sus raíces sobre un escenario fronterizo en permanente construcción, sobre una encrucijada en la que confluyen senderos procedentes de distintos orígenes y de la que parten caminos hacia diferentes destinos; ahora bien, y dado que esa actitud crítica no interesa lo más mínimo a la mayor parte de la industria cultural y editorial y de los medios de comunicación, que funcionan muchas veces como voceros de unos mismos intereses, habrá que aceptar el desafío que dicha conducta nos plantea: leer la palabra desterrada y errante, oír la palabra del otro, un desafío que conlleva, claro, el riesgo de perder nuestra propia identidad, un reto que encontramos en algunos textos literarios que han sabido resistirse a los embates de esa bicha neoliberal que todo lo cosifica, engulle y devora. 


\section{Referencias bibliográficas}

Anderson, Perry (2000): Los orígenes de la posmodernidad. Trad. de L. A. Bredlow. Barcelona, Anagrama.

EAgleton, Terry (2013): El acontecimiento de la literatura. Trad. de R. García Pérez. Barcelona, Península.

ECHEVARRÍA, Ignacio (2005): Trayecto. Un recorrido crítico por la reciente narrativa española. Barcelona, Debate.

GramSCI, Antonio (1973): Cultura y literatura. Sel. y pról. de J. Solé-Tura. Barcelona, Península.

MARX, Karl (1945): Historia crítica de la teoría de la plusvalía. Trad. y pról. de W. Roces. México D. F., FCE.

SAlmon, Christian (2001): Tumba de la ficción. Trad. de T. Kauf. Barcelona, Anagrama.

SANZ, Marta (2014): No tan incendiario. Cáceres, Editorial Periférica.

ŽIŽEK, Slavoj (2009): Sobre la violencia. Seis reflexiones marginales. Trad. de J. A. Fernández. Buenos Aires, Paidós. 